\title{
O Papel das Funções Cognitivas em Praxeologias de Tipos de Tarefas Matemáticas
}

\author{
The Role of Cognitive Functions in Praxeologies of Mathematical Task Types
}

Laerte Silva da Fonseca*a; Edmo Fernandes Carvalho ${ }^{\text {b; }}$ Luciano Pontes da Silvac; Kleyfton Soares da Silvad

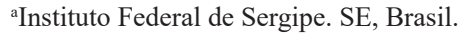 \\ ${ }^{b}$ Universidade Federal do Oeste da Bahia. BA, Brasil. \\ 'Universidade Federal de Alagoas. AL, Brasil. \\ Instituto Federal Goiano. GO, Brasil. \\ *E-mail: laerte.fonseca@uol.com.br
}

\begin{abstract}
Resumo
O objetivo principal deste trabalho é descrever uma análise sobre como as funções cognitivas atuam diretamente em organizações praxeológicas relativas a tipos de tarefas trigonométricas, relevando a complexidade neurocognitiva para realização das mesmas. A metodologia considerou uma pesquisa bibliográfica, ressaltando-se a importância de aproximar elementos da Teoria Antropológica do Didático (TAD) e da Neurociência Cognitiva. Foi verificado que para a realização de tipos de tarefas matemáticas, no campo da Trigonometria, cuja organização praxeológica esteja bem definida é possível atribuí-las aos estudantes como um convite ao desafio e, de forma gradativa, respeitando-se as condições da neurofisiologia do cérebro. Desse modo, possíveis dificuldades de estudantes frente um determinado saber matemático, pode ser atribuído ao tipo de tarefa proposta. O estudo de algumas funções cognitivas corrobora de certo modo com o estudo dessas dificuldades. Permite inclusive, compreender as implicações da falta de sentido das matemáticas escolares na vida do sujeito. Outro ponto importante a ser destacado remete à necessidade dos cursos de formação de professores de matemática oportunizar aos licenciandos conhecimentos de neurociência cognitiva, pois quanto mais se sabe sobre o funcionamento do cérebro, melhor será a escolha dos tipos de tarefas matemáticas para apresentá-las tanto nas salas de aulas, como nos livros didáticos.
\end{abstract}

Palavras-chave: Funções Cognitivas. Praxelogias. Tipos de Tarefas Matemáticas.

\begin{abstract}
The main objective of this work is to describe an analysis of how cognitive functions act directly in praxeological organizations related to types of trigonometric tasks, emphasizing the neurocognitive complexity to perform them. The methodology considered a bibliographical research, highlighting the importance of approaching elements of the Didactic Anthropological Theory and Cognitive Neuroscience. It was verified that for the accomplishment of types of mathematical tasks, in the field of Trigonometry, whose praxeological organization is well defined, it is possible to attribute them to the students as an invitation to the challenge and, in a gradual way, respecting the conditions of the neurophysiology of the brain. Thus, possible difficulties of students in the face of certain mathematical knowledge, can be attributed to the type of task proposed. The study of some cognitive functions corroborates in a way with the study of these difficulties. It even allows us to understand the implications of the lack of meaning of school mathematics in people's lives. Another important point to be highlighted is the need for training courses for mathematics teachers to give graduates the knowledge of cognitive neuroscience, since the more we know about brain functioning, the better the choice of the types of mathematical tasks to present them in classrooms, as in textbooks.
\end{abstract}

Keywords: Cognitive Functions. Praxeologies. Types of Math Tasks.

\section{Introdução}

Neste trabalho, ensejou-se descrever uma análise sobre como as funções cognitivas atuam nas organizações praxeológicas relativas a tipos de tarefas no âmbito da Trigonometria, relevando a complexidade neurocognitiva para realização das mesmas.

Não é novidade que para os alunos realizarem as tarefas matemáticas indicadas pelo professor ou aquelas apresentadas nos livros didáticos dispara-se, em alguns deles, ansiedade, sofrimento ou sentimento de incapacidade. Por esse motivo, muitos desabafam um pensamento que tem ecoado décadas de escolaridade: "eu não gosto ou detesto matemática" (Fonseca, 2008, p.30).

A realização de uma tarefa, seja ela matemática ou não, exige do realizador alguns atributos, tais como: certo nível de conhecimento relativo à tarefa, motivação para resolvê-la e esforço cognitivo. Não obstante, tais ingredientes nem sempre estão disponíveis nos estudantes.

O primeiro deles sinaliza a existência de informações consolidadas na função cognitiva denominada de memória de longo prazo. Para tanto, outro pacote de exigências precisa ser satisfeito em prol dessa demanda: a informação precisa ter sentido e significado, conforme postula Izquierdo (2011), por exemplo. A motivação, segundo Maslow (1968), "brota" de uma sequência hierárquica de necessidades que precisam ser satisfeitas, onde as tarefas matemáticas ocupam o lugar das necessidades secundárias, mais especificamente, a necessidade de autorrealização. Sendo assim, precisar-se-ia que desenvolver uma tarefa matemática representasse uma 
necessidade. Mas, nem sempre isso acontece. Por quê?

Por último, o esforço cognitivo exige treinamento. Para Willingham (2011), pensar é uma tarefa cansativa, vagarosa e incerta. Como pensar é uma tarefa das mais difíceis, são poucos os estudantes que alcançam essa conquista. Esse psicólogo cognitivo acentua ainda que "as pessoas são naturalmente curiosas, mas não são naturalmente boas pensadoras. A menos que as condições cognitivas sejam favoráveis, pensar será evitado" (Willingham, 2011, p. 15).

As evidências apontadas por Izquierdo (2011), Maslow (1968) e Willingham (2011) promovem algumas reflexões: até que ponto as tarefas matemáticas satisfazem as características descritas por esses cientistas cognitivos? Desse modo, a entrada, nessa discussão, do matemático francês Yves Chevallard ajudará a analisar os tipos de tarefas matemáticas, bem como auxiliar em suas concepções de modo a respeitar uma organização que ele denominou de praxeologia.

Para Chevallard (1992), o desenvolvimento humano cobra do indivíduo certo envolvimento com uma atividade. Essa, por sua vez, precisa estar atrelada a alguma instituição que o mobilizará por meio da atribuição de tarefas. De modo particular, as tarefas matemáticas se encontram no cruzamento destes dois conjuntos: atividade humana e instituições sociais. Dessa forma, para os educadores matemáticos brasileiros Fiorentini e Lorenzato (2006), a matemática deveria estar a serviço da educação e não contrariamente, o que pode ser a justificativa dos quadros de reprovação e evasão escolar.

Cuidadosamente, Chevallard (1992) desvelou em sua teoria uma forma de fazer o aluno entrar em atividade matemática, mobilizando o diálogo entre dois blocos que ele denominou, respectivamente, de saber-fazer e saber, sinônimo final do termo praxeologia.

Ocorre que o primeiro bloco, saber-fazer, reúne elementos institucionais, as tarefas e as técnicas, sendo esse último o elo para abordarmos o funcionamento das capacidades cognitivas, sobretudo, as mais requisitadas para tipos de tarefas matemáticas.

Esse pesquisador explica que uma técnica resulta dos procedimentos adequados para a realização de uma tarefa e, nesse sentido, existem técnicas clássicas apresentadas nas aulas de matemática, mas, também, existe a criatividade dos alunos que pode de modo não padronizado encontrar meios para resolver as tarefas.

Essas e outras discussões serão apresentadas nesse artigo que teve sua motivação conduzida pela ausência de uma aproximação da Teoria Antropológica do Didático - TAD com elementos da Neurociência Cognitiva - NC. Enquanto a primeira justifica institucionalmente os porquês de uma organização praxeológica ser mais adequada para fazer o aluno entrar em atividade, a segunda demonstra sob quais condições o funcionamento do cérebro irá permitir ou não a realização dessa mesma atividade.

O texto decorre de uma análise considerando a TAD e algumas evidências científicas da NC. Está subdividido em três sessões, onde: primeiramente apresenta-se sobre as noções de praxeologia de tipos de tarefas; na sequência, discutem-se as funções cognitivas mais ativadas em tipos de tarefas matemáticas e, por fim, como o estado ou condições dessas funções impactam na realização de tarefas.

\section{Noções Sobre Praxeologias de Tipos de Tarefas Matemáticas}

Nesta seção, apresentam-se algumas noções que concernem às praxeologias de tipos de tarefas matemáticas, com o intuito de exploração de mais elementos para compreensão da relação entre tais praxeologias e as funções cognitivas de um sujeito.

Primeiro é preciso destacar que a praxeologia matemática, expressão cunhada por Chevallard (1999), é uma e não a única forma de modelar a Atividade Matemática - AM de um sujeito. Essa atividade matemática pode ser pensada a partir da relação da pessoa com o mundo e com as instituições, relação esta fomentada pelas suas necessidades que devem ser satisfeitas, a exemplo da manipulação de objetos matemáticos, que vai regular e orientar tal atividade (Farias, Carvalho, \& Teixeira, 2018).

A AM não pode ser compreendida apenas do ponto de vista institucional, apesar de ser este o foco nas mais variadas pesquisas no campo da epistemologia experimental. Há que se pensar nos aspectos cognitivos, ou melhor, as funções cognitivas, o que implica numa releitura da noção da AM, mesmo que esta seja institucional. Além disso, no quadro teórico em que se insere esta noção, a Teoria Antropológica do Didático - TAD, postula-se que ensinar e aprender matemática, por exemplo, consiste em ativar atividades de construção das organizações matemáticas e didáticas com o intuito de responder às tarefas problemáticas de um determinado processo de estudo.

Desse modo, a AM pode ser compreendida como a relação de uma pessoa com uma instituição e/ou com o mundo, motivada pela necessidade de mediar objetos matemáticos, expressada na resolução de tarefas matemáticas, e "mediada pelo reflexo psicológico” (Leontiev, 1978, p. 66). É importante discutir inicialmente essa noção, que assim como a de praxeologias matemáticas, é central no âmbito da Teoria Antropológica do Didático. A ideia de atividade matemática é uma das razões de ser da utilização da noção de praxeologia.

Dito isto, cabe destaque nesse estudo, a estrutura da noção de praxeologia, e a referência a ela será sempre feita associada a um saber. Segundo Chevallard (1999), elas podem ser de duas espécies: mtemáticas ou didáticas. No entanto, o cerne nesse estudo são as praxeologias matemáticas, também chamadas de organizações matemáticas.

Na concepção chevallardiana, a praxeologia matemática é a junção de dois blocos: saber-fazer, ou técnico-prático, e saber, conhecido como tecnológico-teórico, e a noção de tarefa seu sustentáculo. Ainda de acordo com a concepção 
supracitada, aprender ou ensinar matemática são ações humanas, sobre as quais se admite serem modeladas pela praxeologia matemática, o que consiste em realizar uma tarefa $t$ de um determinado tipo $T$, que pode ser cumprida por uma determinada técnica $\tau$, que por sua vez é fundamentada por uma tecnologia $\theta$, e legitimada por meio de uma teoria $\Theta$. Simbolicamente esşa estrutura é comumente representada por $\wp=[T, \tau, \Theta, \Theta]$.

Uma técnica $(\tau)$ é uma maneira de fazer ou realizar as tarefas, assim $\tau \in$ t. Para Chevallard (1999), uma praxeologia referente a um tipo de tarefa $t$ necessita de uma técnica $\tau$ relativa. Mas, ele salienta que uma determinada técnica $\tau$ pode não ser suficiente para realizar todas as tarefas em torno daquele objeto do saber especifico. Uma técnica pode funcionar para uma parte das tarefas t e fracassar para outra. Isso porque em uma praxeologia pode existir uma hierarquização de técnicas, pelo menos no que tange à realização de certo número de tarefas t (Chevallard, 1999).

Nesse ínterim, a tecnologia $\theta$ além de representar o discurso racional que justifica uma técnica, ou seja, explicitar as condições para que uma técnica permita que se cumpra uma tarefa do tipo T, também tem a função de produção de novas técnicas mais eficazes na realização das tarefas. E a teoria $\Theta$ tem a missão de tornar inteligível o discurso tecnológico, dar sentido aos problemas levantados e permitir interpretação das técnicas e fundamentação das descrições e demonstrações tecnológicas (Trigueiros, Bosch, \& Gascón, 2010), o que segundo Chevallard (1999) nem sempre acontece devido à abstração dos enunciados teóricos normalmente apresentados.

Em suma, $\wp$ indica um conjunto de técnicas no seio de uma tecnologia e de uma teoria organizadas para um tipo de tarefa, denominada Organização Praxeológica Pontual (OMP), isso porque envolve apenas um tipo de tarefa T. Esperavase que nessa OMP os blocos práticos $[T, \tau]$ e teóricos $[\theta, \Theta]$ fossem inseparáveis.

Um dos postulados da TAD, referente às possíveis dificuldades dos sujeitos diante de tarefas matemáticas, dá conta do papel central dessas tarefas. Em outras palavras, as dificuldades dos sujeitos começam com o tipo de tarefas que lhes são ofertadas. Como poderá ser visto na seção 4 , existe uma razão de ser para considerar as funções cognitivas no estudo das praxeologias matemáticas, apontada por Fonseca (2015).

Uma tarefa que, por exemplo, tenha como objetivo determinar a amplitude e a imagem de uma função, dada por é um tipo de tarefa, mas o verbo determinar não explicita o quê determinar. Desse modo, só se tem um tipo de tarefa se o objetivo é determinar a amplitude e a imagem da referida função. No caso acima, determinar é gênero da tarefa.

Normalmente, uma Organização Matemática (OM) é elaborada em torno de objetos não ostensivos (uma noção, ou conceito), inerentes à própria Matemática (Barbosa \& Brito Lima, 2015) que dependem dos objetos ostensivos escriturais e/ou figurais. Desse modo, as Praxeologias Matemáticas são as respostas às questões sobre as formas de realizar o estudo de determinado tema (objeto do saber ou associado a ele), por exemplo, determinar a amplitude de uma função composta .

Ademais, tem sido alvo das preocupações de pesquisadores no campo da didática das ciências, o tipo de relação existente entre os blocos que compõem a praxeologia matemática, a exemplo do que é mostrado em Fonseca et al. (2010), ao levantar hipótese que no sistema de ensino espanhol as organizações matemáticas se concentravam no bloco práticotécnico, estando esse de certo modo dissociado ou sofrendo incidência exígua do bloco tecnológico-teórico sobre a atividade matemática que se realiza efetivamente, o que não difere do problema supostamente enfrentado no Brasil.

Apesar de afirmar que não existe uma praxe (bloco do saber-fazer) desacompanhada de um logos (bloco do saber), Chevallard (2009) reconhece que no processo de ensinoaprendizagem, esse segundo bloco parece ausente nas praxeologias, porque não estão visíveis ou são pouco visíveis, implicando, nesse sentido, em praxeologias incompletas.

Sob uma influência implícita, culturalmente construída, as praxeologias matemáticas têm sido (re)construídas sob um paradigma em que se considera os saberes monumentos, em detrimento a outro paradigma no qual propõe-se o questionamento da natureza das coisas: Paradigma da Investigação e Questionamento do Mundo (PIQM).

Nesse sentido, as praxeologias matemáticas são caracterizadas por uma evitação do processo de questionamento das técnicas utilizadas, o que pode ser a causa do processo de atomização dessas praxeologias, mas que também pode ser resultado de outro fenômeno didático.

No que se refere ao processo de ensino-aprendizagem dos ostensivos ${ }^{1}$ do campo da trigonometria, Klein e Costa (2011) destacam, a partir das suas experiências docentes de mais de duas décadas, que os alunos apresentam dificuldades na assimilação dos conceitos trigonométricos. No entanto, tal constatação pode ser melhor compreendida sob a ótica da TAD, especialmente se for considerado o papel dos fenômenos didáticos ${ }^{2}$. Essas dificuldades devem compor um determinado fenômeno, que por sua vez pode ter sua compreensão complementada pelo estudo das funções cognitivas, especialmente as funções executivas (raciocínio, planejamento, monitoramento), visto que essas dão corpo aos

\footnotetext{
1 Referindo-se ao que Chevallard chamou de objetos que são manipuláveis na realização da atividade matemática, percebidos com algum de nossos sentidos. Já os objetos não ostensivos são aqueles que, presentes numa organização matemática, não são percebidos com os sentidos.

2 Segundo Chevallard (2013), são construções teóricas dos fatos, ou a contrapartida as muitas faces dos fatos empíricos (mas nos referimos aos fatos didáticos). No entanto, Chevallard diz que "[...] os fenômenos se referem a esses fatos que a teoria nos permite definir em sua própria linguagem e conceitos. "(Chevallard, 2013, p.5). No contexto desse estudo, infere-se que o fenômeno em questão seja o da monumentalização dos saberes (Chevallard, 2006).
} 
pensamentos, sentimentos e ações dos sujeitos.

No contexto da Didática da Matemática, a tentativa de caracterização de fenômenos didáticos é quase uma obrigação. Mas, antes observa-se fatos que são os elementos observáveis, o que explicitamente se mostra a exemplo dos alunos detestarem matemática e externalizarem isto, ou terem dificuldades de compreenderem as noções trigonométricas. O fenômeno requer uma lente teórica para ser compreendido ou é ele mesmo a teorização do fato, daquilo que vai justificálo. E nesse ponto faz urgente salientar uma certa lacuna nesse trabalho de caracterização dos fenômenos didáticos da percepção e da consideração do papel das funções cognitivas.

Como será visto adiante, o estudo de algumas das funções cognitivas corrobora com o estudo das dificuldades dos estudantes no campo da trigonometria. Permite ainda compreender as implicações da falta de sentido das matemáticas escolares, fenômeno caracterizado por Fonseca et al. (2010) que tem implicações inclusive na relevância dos currículos da matemática e até a incapacidade de percepção da matemática na sociedade.

Apesar do cerne das discussões aqui ser as praxeologias matemáticas, as noções apresentadas por Chevallard (1999) são gerais, ou seja, pode-se falar em praxeologias da Física, da Química, da História, etc., e das praxeologias didáticas, pois essas têm papel preponderante na forma como as praxeologias disciplinares específicas serão (re)construídas nas instituições. Nesse sentido, Andrade e Guerra (2014, p.1203), argumentam:

(...) as praxeologias didáticas ou organizações didáticas são as respostas às questões de como estudar, ou seja, de como organizar e articular um determinado tema com outros segundo uma intencionalidade que dê razão ao estudo, portanto, as praxeologias não são criações da natureza, mas "artefatos", ou "obras", construídas pelo homem para ajuda ao estudo que são corporificadas nos documentos oficiais, nos livros didáticos, em uma sala de aula, nos cadernos dos estudantes, etc.

Essas organizações didáticas representam as escolhas didáticas a serem realizadas no estudo da matemática e são respostas aos questionamentos do tipo: Como organizar o estudo de determinado conteúdo matemático? Ou como realizar a abordagem de um objeto da matemática? E fundamentalmente seu objetivo é permitir a existência da (re)construção de uma praxeologia matemática. Outrossim, considerando o papel das funções cognitivas o questionamento pode ser: como realizar a abordagem de um objeto matemático levando em conta os variados tipos de funções cognitivas?

\section{As Funções Cognitivas Ativadas em Tipos de Tarefas Matemáticas}

Traz uma discussão sobre as funções cognitivas que são devidamente ativadas, quanto às praxeologias matemáticas, dentro da AM. Faz-se necessário, destarte, conceituar as funções cognitivas que estão engendradas nesse propósito.

Dentro da Neuropsicologia Cognitiva duas teorias se destacam na tentativa de explicitar a linguagem matemática e os processos cognitivos, também denominada linguagem quantitativa e aritmética, a saber: A teoria de Myklebust (1965) que propõe o desenvolvimento cognitivo durante cinco fases: sensação, percepção, imagem, simbolização e conceitualização. Já a segunda teoria, preconizada por Piaget e Inhelder (1995) falam de quatro etapas: estádio sensóriomotor, estádio pré-operatório, estádio das operações concretas e estádio das operações formais.

A primeira teoria apresenta a primeira fase como o primeiro contato básico de experiência humana (Cruz, 2009). Trata-se de trazer à tona estímulos para determinado fim, no caso específico, a aprendizagem matemática. A segunda, percepção, profere a seleção dos estímulos, já a nível cerebral no tratamento informacional, onde a região frontal é ativada com as funções executivas e a atenção seletiva (Lent, 2008).

Na terceira fase, denominada imagem, trata-se do processo no qual o aprendiz identifica ou diferencia em relação a um objeto, uma percepção ou até mesmo da informação de uma percepção secundária, situada no passado. Isto desvela a atuação da memória de longo prazo, que no modelo de Atkinson-Schiffin, após as informações passarem pela memória sensorial, todas as unidades do objeto selecionadas pelo processo atencional ficam na memória de curto prazo até serem direcionadas para a memória de longo prazo (Maia, 2010).

Não há uma região específica do cérebro para se localizar a função da memória, porém o hipocampo, situado dentro do lóbulo temporal central, direciona as sinapses na tentativa de evocar certos objetos, isto é, criando imagens. Um paralelo com a TAD seria no momento da evocação dos objetos não ostensivos em detrimento aos estímulos, objetos ostensivos e sua manipulação, denominada por Silva (2019) como a dialética ostensivo/não ostensivo.

A quarta fase, simbolização, é caracterizada pela capacidade cognitiva de representar e resumir as experiências necessárias por meio de símbolos, permitindo, assim, o raciocínio em sua forma concreta. Sendo assim, a região do córtex frontal e a parietal, esta última responsável pela linguagem formal (Broca e Wernicke) são ativadas.

Já na quinta e ultima fase segundo esse modelo, a conceitualização se configura como o estágio mais avançado na cognição humana (Maia, 2010). O processo cognitivo permite classificar e organizar as ideias de forma concisa; neste caso, as áreas supracitadas acima trabalham em conjunto, onde as percepções se traduzem em atribuições significativas, permitindo, assim, a elaboração sofisticada de pensamentos, além de sua expressividade.

No segundo modelo, oriundo de Piaget, a primeira fase (sensório-motor/0 a 2 anos) consiste em uma aprendizagem por experiências, no quesito cinestésico, pois não há expressão de ideias por meio da linguagem e sim por comportamentos vicariantes (Fonseca, 1999). Nesse caso, a criança está ligada ao processo exploratório quando relacionado à aprendizagem.

No pré-operatório ( 2 a 7 anos), nota-se a presença, de forma 
embrionária, de simbolização, concatenada com os jogos de pensamento criativo e expressividade gráfica, fazendo assim com que a criança seja capacitada a julgar tamanho, forma e relações. Nesse caso, segundo Maia (2010, p. 3) o aprendiz desenvolve "um entendimento rudimentar da matemática, no qual estão presentes conceitos de linguagem, como 'mais', 'metade', etc."

Para o estágio das operações concretas (7 a 12 anos) o pensamento lógico já se encontra presente, facilitada por estímulos como figuras concretas e situações cotidianas (Fonseca, 1999). Assim, o pensamento lógico-matemático conduz a criança a adquirir a aprendizagem aritmética.

No último estágio, o das operações formais (12 anos em diante), a criança já consegue raciocinar e chegar a conclusões lógicas sobre determinado problema (Casas, 1988). Nesta fase, a aprendizagem é abrangente no sentido de criar uma linguagem matemática robusta e podendo fazer associações com os objetos ostensivos e não ostensivos.

Os dois modelos apresentam cruzamentos para explicar como as funções cognitivas atuam no processo de aprendizagem, mesmo o segundo trazendo uma perspectiva desenvolvimentista. Porém, ambos explicitam a questão de apresentar experiências concretas (ou estímulos) até a formalização lógica, onde cada etapa desse processo se dá articulando as áreas específicas do cérebro.

O Quadro 1 mostra em paralelo os dois modelos e como a questão do sensorial ao abstrato percorre por cada etapa:

Quadro 1 - Paralelismo entre os Modelos de Myklebust (1965) e Piaget e Inhelder (1995) e dialética sensorial/abstrato

\begin{tabular}{|c|c|c|}
\hline $\begin{array}{l}\text { Myklebust } \\
\text { (1965) }\end{array}$ & $\begin{array}{c}\text { Piaget e } \\
\text { Inhelder (1995) }\end{array}$ & $\begin{array}{c}\text { Dialética (Sensorial/ } \\
\text { Abstrato) }\end{array}$ \\
\hline Sensação & Sensório-Motor & \\
\hline Percepção & Pré-operatório & \\
\hline Imagem & $\begin{array}{l}\text { Operações } \\
\text { Concretas }\end{array}$ & \\
\hline Simbolização & $\begin{array}{l}\text { Operações } \\
\text { Formais }\end{array}$ & \\
\hline Conceitualização & - & \\
\hline
\end{tabular}

A dialética se refere aos gestos que mobilizam representações que não correspondem a nenhum dado sensorial/concreto, e o que é concreto ou resultante das atividades dos órgãos sensoriais. Sua forma cíclica, não é apresentada no modelo de desenvolvimento, porém é necessário que os estímulos sejam repostos em sua concretude e averiguados já na fase conceitual ou das operações formais, onde as funções cognitivas que concernem, neste caso com a aprendizagem, possam ser reativadas com mais interconexões, como é o caso da conceitualização no primeiro modelo, onde partes variadas do cérebro trabalham em conjunto.

$\mathrm{Na}$ questão da linguagem quantitativa, esse pressuposto de uma dialética entre o concreto e o abstrato corrobora com a praxeologia proposta na TAD, onde o discurso entra em consonância com o logos. Fica, portanto, incumbida à próxima seção a atualização dessas funções cognitivas e como elas influenciam a realização de tipo de Tarefas matemáticas.

\section{Influência das Funções Cognitivas na Realização de Tipos de Tarefas Matemáticas}

Estar diante de uma tarefa matemática e realizá-la, com êxito, exige do sujeito-aluno duas frentes que, apesar de diferentes, precisam funcionar sobre uma orquestrada sinfonia: primeiramente, o nível de homeostase das funções cognitivas e, em segundo lugar, da praxeologia relacionada ao tipo de tarefa matemática.

Como é o cérebro o berço dessas funções, existe uma relação direta sobre a possibilidade ou não de realização de tarefas matemáticas. A Figura 1 desenvolvida por Fonseca (2015) descreve como se dá o funcionamento do processamento de uma informação que se faz necessária entender para depois conectá-la com tarefas matemáticas. Além disso, atualiza as ideias teóricas de Myklebust (1965) e Piaget e Inhelder (1995) discutidas na seção anterior.

Figura 1 - Circuitaria das Funções Cognitivas

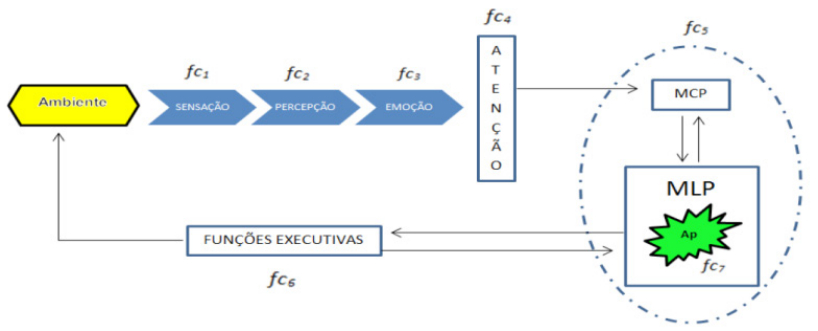

Fonte: Fonseca (2015, p. 189).

Segundo esse pesquisador, são sete as funções cognitivas ( $f c_{n}$, com $n 1 \leq \mathrm{n} \leq 7$ ) descritas acima, onde MCP (memória de curto prazo), MLP (memória de longo prazo) e AP (aprendizagem).

Considerando os fundamentos da seção anterior sobre a ativação das funções cognitivas em tipos de tarefas matemáticas, reside no sistema límbico o lócus essencial para que tais tarefas possam ser consideradas, pelos alunos, para uma possível resolução. Mas, por que isso precisa acontecer?

Conforme explica Ledoux (2001), esse sistema é responsável por controlar a função $f c_{3}$, em que a partir do tipo de estimulação ambiental (recursos mobilizados pelo professor) outras estruturas desse sistema serão requisitadas simultaneamente para julgar e decidir pela importância do tipo de informação que solicita processamento cerebral.

Dentre as subestruturas mais exigentes e recorrentes estão o núcleo accumbens, o tálamo, o hipotálamo e o hipocampo. Segundo Lente (2008), o primeiro busca verificar se o tipo de informação oferece duas condições essenciais: prazer e sentido (utilidade). Em outras palavras, não será qualquer tipo de tarefa matemática que funcionará como um convite para o aluno, mas aquela, ao menos inicialmente, que justifique o consumo de energia cerebral para tal realização. 
Gazzaniga (2006) reforçam as expectativas citadas acima, esclarecendo que cabe ao tálamo (uma espécie de secretária do cérebro) direcionar o rumo da informação depois de uma "consulta" ao hipotálamo (que controla todas as vias de comunicação do sistema emocional) e do hipocampo (responsável pelas informações na MLP).

Por hipótese, existe um tipo de tarefa que reúna todas essas condições. Então, pode-se considerar que um conjunto de substâncias químicas (neurotransmissores) será liberado apresentando o comportamento de interesse esperado pelo professor. Essas substâncias, serotonina, acetilcolina, adrenalina e noradrenalina representam as ferramentas para articular os mecanismos atencionais fundamentais na realização da tarefa: bottom-up e top down. O primeiro é ativado pelas características do estímulo ambiental, enquanto o segundo pela existência de conhecimentos prévios na MLP (Posner \& Petersen, 1990).

Desse modo, até aqui caracterizou-se um lado da fronteira da nossa discussão, o órgão responsável pelo desenvolvimento da aprendizagem matemática (cérebro), por exemplo, definindo rapidamente as condições básicas esperadas pelo mesmo.

Do outro lado da fronteira encontram-se os tipos de tarefas matemáticas que justificarão os alunos entrarem em atividade, segundo postula Chevallard (1992). Entretanto, é preciso que exista, também, uma organização praxeológica ou praxeologia em torno da(s) tarefa(s) proposta(s).

Conforme apresentado na primeira seção desse artigo, uma praxeologia relaciona dois blocos: o primeiro, práticotécnico, sinônimo de saber-fazer e, o segundo, tecnológicoteórico, unívoco de saber.

Diante de um tipo de tarefa matemática (o saber questionado) o estudante precisa dispor de ferramentas (o fazer, as técnicas) para efetivá-la. A parte primeira desse bloco visa compreender se existe no aluno o domínio desse saber, enquanto na segunda, se ele também aprendeu novas ferramentas relativas à tarefa dada, bem como outras que poderão ser necessárias possivelmente armazenadas na MLP, caso existam. Esse bloco está atrelado ao bloco do saber, constituído de tecnologia e teoria (Chevallard, 1992), onde repousam todas as justificativas teóricas e de reformulação das técnicas do primeiro bloco.

Inicia-se, dessa forma, a visualização da articulação entre alguns elementos da TAD e da NC não discutidos nas pesquisas de Chevallard (1992, 1994,1998, 2002a, 2003, 2007), por exemplo, e nem por pesquisadores da neurociência cognitiva, tais como: Posner e Petersen (1990), Kandel (1991), Ledoux (2001), Gazzaniga (2006), Lent (2002, 2008), Pillon (2008), Izquierdo (2011), Willingham (2011) e Redolar (2014), entre outros.

Com efeito, pode-se questionar: Mas, por que compreender essa articulação importa ao ensino-aprendizagem de matemática? Uma resposta imediata está abrigada em Fonseca (2015) quando demonstrou em sua pesquisa que o entendimento da máquina cerebral é condição sine qua non para elaborar ou pinçar tipos de tarefas matemáticas que considerem as expectativas do encéfalo, pois caso contrário o cenário de apatia discente permanecerá sinalizando a falta de interesse dos alunos em aprender matemática da forma como ela tem sido apresentada.

Explicam Fonseca et al. (2017) que a partir da noção de ecologia de Chevallard (1998, 2002a, 2002b) é possível, cautelosamente, apresentar um tipo de tarefa matemática embasada numa organização praxeológica, pois nessa existem dois tipos de objetos que dialogam diretamente com as subestruturas do sistema límbico: os objetos ostensivos e os objetos não ostensivos.

Para exemplificar, pode-se considerar a tarefa tradicional e simples que requisitam técnicas básicas conhecidas no Ensino Fundamental (substituição de incógnitas) e técnicas relacionadas à compreensão da definição de cosseno no ciclo trigonométrico apresentadas no Ensino Médio: "Dada uma função, determinar em ". É importante destacar que esse tipo de tarefa não satisfaz as condições essenciais esperadas pelo sistema límbico, embora seja importante para o treinamento e fixação da aprendizagem das funções trigonométricas. Tal impasse sugere cautela em sua análise.

Então, como se dá o funcionamento cerebral para o processamento dessa informação? Os objetos ostensivos escriturais podem não ser capturados pelo mecanismo atencional bottom-up porque o núcleo accumbens questionará a utilidade e o prazer na realização dessa tarefa e, sendo assim, haverão alunos que irão bloquear a articulação com o mecanismo top down, onde podem existir os conhecimentos prévios armazenados no hipocampo, os objetos não ostensivos. Por outro lado, diferentes alunos poderão agir no "automático" e evocar e aplicar as técnicas esperadas para solucionar a tarefa.

Enquanto pesquisadores que arriscam fundar nossas investigações na articulação entre a TAD e NC, entendemos que se apropriar do saber matemático é uma tarefa indiscutível já tratada exaustivamente nos documentos oficiais, mais recentemente na Base Nacional Comum Curricular (Brasil, 2017). Entretanto, para que isso possa ocorrer faz-se necessário submetê-la às condições neurocognitivas. Para o aluno compreender que o treinamento é importante para se tornar hábil na resolução de tarefas desse tipo, antes, ele precisa ser submetido a tarefas que o sensibilizem. Por exemplo: "Calcular o ângulo de inclinação para construção de uma rampa para pessoas com necessidades especiais, considerando o comprimento horizontal de $3 \mathrm{~m}$ e a $\operatorname{tg} \theta<$ ".

Essa é, também, uma tarefa básica. Mas, sinaliza uma utilidade para o bem estar social. Talvez, seja esse um tipo de estímulo que sensibilize a região límbica (o prazer em saber como ajudar alguém) para que ocorra a interação entre os mecanismos bottom-up e top down que, respectivamente, estão diretamente associados aos objetos ostensivos e não ostensivos. 
Não obstante, o treinamento precisa ser gerenciado gradativamente, onde a sensação de prazer e utilidade imediatos precisa ceder espaço para a instalação de um raciocínio eficiente e eficaz, alcançando, dessa forma, os objetivos previstos pelo ensino de matemática.

Dadas essas considerações foi possível apresentar alguns exemplos sobre o papel das funções cognitivas, invisíveis aos olhos dos professores, ao mesmo tempo presente neles próprios, mas talvez esquecidos das experiências enquanto alunos.

Ao mesmo tempo, como na TAD, por exemplo, ocupouse de fazer referências ao meio mais interno do indivíduo, o cérebro, permitindo a construção e fortalecimento da presente articulação introduzida por Fonseca (2015), alternada por Silva (2018) quando relacionou a geometria molecular a MLP e a Silva (2019) que tratou da etiologia e tipologia dos erros cometidos durante a aprendizagem das funções trigonométricas considerando os fundamentos da atenção seletiva.

Esse movimento demonstra tanto a importância de investigar mais profundamente essa articulação, bem como oportuniza aos cursos de formação de professores de matemática uma atualização na área.

\section{Conclusão}

O objetivo principal desse trabalho foi descrever uma análise sobre como as funções cognitivas atuam diretamente em organizações praxeológicas relativas a tipos de tarefas trigonométricas, relevando a complexidade neurocognitiva para realização das mesmas.

Para tanto, recorreu-se aos pressupostos teóricos da TAD e da NC, buscando uma articulação para justificar a importância das funções cognitivas na realização de tipos de Tarefas trigonométricas, por exemplo.

Ficou evidente que duas condições precisam coexistir: primeiramente que exista uma praxeologia em torno de um tipo de tarefa e que, em segundo lugar, essa atenda às exigências do funcionamento do cérebro, principalmente do sistema límbico.

Assim, os objetos ostensivos e não ostensivos previstos pela TAD podem dialogar com os mecanismos atencionais bottom-up e top down permitindo que se origine a motivação e imersão do aluno para solucionar a tarefa, pois ela passa nesse momento a representar um desafio que se traduz para o cérebro como algo que tem sentido e significado.

Nesta perspectiva, defende-se que as instituições, seja a partir dos documentos oficiais, bem como as escolas busquem considerar o entendimento dos processos mentais como mais uma alternativa para minimizar o desconforto de aprender conteúdos que, nem sempre, são de interesse dos alunos, já que não atendem suas necessidades imediatas.

É na adolescência que o imediatismo ocorre em potencial. Então, precisa-se de artifícios para contornar os "radares" cerebrais, especificamente, o núcleo accumbens para inserir, gradativamente, noções trigonométricas consideradas importantes para o amadurecimento do cérebro, pois apenas dessa forma outras funções cognitivas superiores, como julgamento e decisão (funções executivas), poderão estar disponíveis na fase adulta.

Assim, buscou-se nesse texto mobilizar uma discussão nos cursos de formação de professores (inicial ou continuada) sobre o cérebro, sua estruturas, subestruturas, funcionamento e interação com o meio.

\section{Referências}

Andrade, R. C. D. \& Guerra, R. B. (2014). Tarefa fundamental em um percurso de estudo e pesquisa: um caso de estudo para o ensino da Geometria Analítica. Educ. Matem. Pesq., São Paulo, 16(4), 1201-1226.

Barbosa E. J. T. \& Brito Lima, A. P. A. (2015). O que os programas de ensino brasileiro preconizam sobre equações do primeiro? Uma análise à luz da Teoria Antropológica do Didático. In: Anais do XIV CIAEM-IACME, Chiapas, México, pp.1-12.

Brasil. (2017). Ministério da Educação. Base Nacional Comum Curricular. Brasília: MEC.

Casas, A. M. (1988). Dificultades en el aprendizaje de la lectura, escrita y cálculo. Valencia: Promolibro.

Chevallard, Y. (1998). Analyse des pratiques enseignantes et didactique des mathématiques: l'approche anthropologique. Cours donné à l'université d'été Analyse des pratiques enseignantes et didactique des mathématiques, La Rochelle, 4-11 juillet 1998; paru dans les actes de cette université d'été, IREM de ClermontFerrand, p. 91-120.

Chevallard, Y. (2009). Approche Anthropologique du Rapport au Savoir et Didactique des Mathematics. Recherches en Didactique des Mathématiques, 12(1), 1-8.

Chevallard, Y. (1992). Concepts fondamentaux de la didactique: perspectives apportées par une approche anthropologique . Recherches en didactique des mathématiques, Grenoble: La Pensée Sauvage.

Chevallard, Y. (1999). L'analyse des pratiques enseignantes en Théorie Anthropologie Didactique. Recherches en Didactiques des Mathématiques, pp. 221-266.

Chevallard, Y. (2007). Le développement actuel de la TAD : pistes et jalons. Notes pour un exposé donné le 6 juin 2007 au Séminaire DIDIREM (Université Paris 7).

Chevallard, Y. (2002a). Organiser l'étude: 1. Structures \& fonctions: Actes XIe école d'été de didactique des mathématiques. Grenoble: La Pensée Sauvage.

Chevallard, Y. (2002b). Organiser l'étude: 3. Ecologie \& regulation: Actes XIe école d'été de didactique des mathématiques. Grenoble: La Pensée Sauvage.

Chevallard, Y. (1994). Ostensifs et non-ostensifs dans l'activité mathématique. Séminaire de l'Associazione Mathesis, Turin, 3 février 1994, in Actes du Séminaire 1993-1994, 190-200.

Chevallard, Y (2003). Rapport au savoir et didactiques. Paris: Éditions Fabert.

Chevallard (2006). Passé et présent de la théorie anthropologique du didacttique. In H. Ruiz Sociedad, esculea y matemáticas. Aportaciones de la Teoria antropológica de lo didático (TA). Jaén: Universidad.

Cruz, V. (2009). Dificuldades de aprendizagem especificas. 
Lisboa: Lidel.

Farias, L. M. S., Carvalho, E. F., Teixeira, B. F. (2018). O trabalho com funções à luz da incompletude do trabalho institucional: uma análise teórica. Educ. Matem. Pesq., 20(3), 97-119.

Fiorentini, D. \& Lorenzato, S. (2006). Investigação em educação matemática: percursos teóricos e metodológicos. Campinas: Autores Associados.

Fonseca, C. et al. (2010). Los REI en la creacion de secuencias de enseñanzay aprendizaje. In: Anais do 3 International Conferenceonthe Anthropological Theoryofthe Didactic. Catalunya, Spain. pp. 247- 256.

Fonseca, L. et al. (2017). Uma ecologia dos mecanismos atencionais fundados na neurociência cognitiva para o ensino de matemática no século XXI. Caminhos da Educação Matemática em Revista/Impressa, 10(1), 19-30.

Fonseca, L. S. (2008). Ensaios de Educação Matemática no Ensino Médio. Aracaju: Info Graphics.

Fonseca, L. S. (2015). Um estudo sobre o Ensino de Funções Trigonométricas no Ensino Médio e no Ensino Superior no Brasil e França. 1v. 495p. Tese de Doutorado. Universidade Anhanguera de São Paulo, São Paulo.

Fonseca, V. (1999). Insucesso escolar: abordagem psicopedagógica das dificuldades de aprendizagem. Lisboa: Âncora.

Gazzaniga, M. S. (2006). Neurociência Cognitiva: a biologia da mente. Porto Alegre: Artmed.

Izquierdo, I. (2011). Memória. Porto Alegre: Artmed.

Kandel, E. et al. (1991). Principles of Neural Science. Nova York: McGraw-Hill.

Klein, M. E. Z \& Costa, S. S. C. (2011). Investigando as Concepções Prévias dos Alunos do Segundo Ano do Ensino Médio e seus Desempenhos em alguns Conceitos do Campo Conceitual da Trigonometria. Bolema, Rio Claro (SP), 24(38), 43-73.

Ledoux, J. (2001). O cérebro emocional: os misteriosos alicerces da vida emocional. Rio de Janeiro: Objetiva.

Lent, R. (2002). Cem bilhões de neurônios. Rio de Janeiro: Atheneu.

Lent, R. (2008). Neurociência da Mente e do Comportamento.
Rio de Janeiro: Guanabara Koogan.

Leontiev, A. N. (1978). O desenvolvimento do psiquismo. Lisboa: Livros Horizonte.

Maia, V. (2010). Funções neuropsicológicas e desempenho matemático: um estudo com crianças da $2^{\mathrm{a}}$ série. Porto Alegre: Universidade Federal do Rio Grande do Sul.

Maslow, A. H. (1968). Introdução à psicologia do ser. Rio de Janeiro: Eldorado.

Myklebust, H. (1965). Development and disorders of written language. New York: Grune \& Sratton.

Piaget, J. \& Inhelder, B. (1995). A psicologia da criança. Porto: Edições Asa.

Pillon, J. (2008). Neurosciences Cognitives et Conscience: comprendre les propositions des neuroscientifiques et des philosophes. Lyon: Chronique Sociale.

Posner, M. I. \& Petersen, S. E. (1990). The attention system of the human brain. In: Annu Rev Neurosci, 13, p. 25-42.

Redolar Ripoll, D. (2014). Neurociência Cognitiva. Editorial Médica Panamericana: Madrid.

Silva, K. S. (2018). A neurociência cognitiva como base da aprendizagem de geometria molecular: um estudo sobre atributos do funcionamento cerebral relacionados à memória de longo prazo. 200p. Dissertação (Mestrado Acadêmico em Ensino de Ciências e Matemática) - Universidade Federal de Sergipe, São Cristóvão.

Silva, L. P. (2019). Um estudo da Atenção Seletiva na aprendizagem das Funções Trigonométricas: etiologias e tipologias de erros na perspectiva da Neurociência Cognitiva. 215p. Dissertação (Mestrado Acadêmico em Ensino de Ciências e Matemática) - Universidade Federal de Sergipe, São Cristóvão.

Trigueros, M., Bosch, M., Gascón, J. (2010). Tres Modalidades de diálogo entre APOS y TAD. In: Bosch, M., Gascón, J., Ruiz Olarría, A., Artaud, M., Bronner, A., Chevallard, Y., Cirade, G., Ladage, C. \& Larguier, M. Un panorama de la $T A D$, p. 77-116, III Congreso Internacional sobre la TAD, Sant Hilari Sacalm.

Willingham, D. T. (2011). Por que os alunos não gostam da escola? Reposta da ciência cognitiva para tornar a sala de aula atrativa e efetiva. Porto Alegre: Artmed. 